\title{
Knowledge and Attitude Towards Tobacco Smoking among 13-15 Year-Old School Children in Viet Nam - Findings from GYTS 2014
}

\author{
Nguyen Thanh Huong ${ }^{1}$, Nguyen Trung Kien ${ }^{1 *}$, Kim Bao Giang², Hoang Van \\ Minh $^{1}$, Phan Thi Hai ${ }^{3}$, Doan Thu Huyen ${ }^{3}$, Luong Ngoc Khue ${ }^{3}$, Nguyen Thuy \\ Linh $^{3}$, Nguyen Tuan Lam ${ }^{4}$, Pham Thi Quynh Nga ${ }^{4}$
}

\begin{abstract}
Studies have shown that smoking is a learnt behavior, often initiated during adolescence. This paper aims to describe tobacco-related knowledge, attitude and associations among school adolescents aged 13-15 with exposure to anti-smoking information. Using data from the Global Youth Tobacco Survey (GYTS) in Viet Nam, 2014, knowledge was measured through 4 questions about tobacco use, and attitude was assessed through 3 questions on personal, social and environmental aspects. Students giving most anti-tobacco responses to all questions were considered as having correct knowledge or appropriate attitude or both. Access to anti-smoking information was determined by exposure to any media messages on tobacco control during the past 30 days and teaching in school about the danger of tobacco use during the past 12 months. A substantial percentage of students thought that being near others who smoke might be harmful to them and smoking is harmful to health (89.4\% and $89.6 \%$ respectively). However, only $46.4 \%$ reported that it is definitely difficult to quit smoking and 66.9\% thought that smoking for only 1 or 2 years, once stopped, is harmful to health. Slightly more than half of the respondents reported appropriate attitude that young smokers have fewer friends than others and smoking makes them less attractive and less comfortable at social events. Noticing anti-smoking messages in the media together with having lessons in school about the dangers of tobacco substantially increased the likelihood of having correct knowledge, appropriate attitude and both. Despite relatively high awareness about smoking harms, effective educational communication is still highly needed to improve the level of comprehensive knowledge and an appropriate attitude regarding tobacco use.
\end{abstract}

Keywords: Tobacco smoking - knowledge - attitude - school children - GYTS 2014 - Viet Nam

Asian Pac J Cancer Prev, 17 Tobacco Prevention and Control in Vietnam Suppl, 37-42

\section{Introduction}

Tobacco use causes nearly 6 million deaths per year worldwide, and current trends show that tobacco use will cause more than 8 million deaths annually by 2030 (WHO, 2011; WHO, 2014). The Association of Southeast Asian Nations (ASEAN) region accounts for almost $10 \%$ of these deaths, i.e. one out of every five lives lost is due to tobacco (VINACOSH and SEATCA, 2014).

Viet Nam has the third highest rate of adult smokers among ASEAN countries. According to Global Adult Tobacco Survey (GATS) in 2010, the percentage of adult male smokers in Viet Nam was $47.4 \%$ (Ministry of Health et al, 2010). Given the known effects of smoking on morbidity and mortality and the nature of smoking habits established during adolescence, changes in smoking behaviors carry extraordinary implications for the health of these youngsters throughout their lives. The battle against tobacco use remains one of the most important public health challenges faced by Viet Nam. Recognizing the importance of tobacco control, Viet Nam has issued the National Policy on Tobacco Control in August 2000 and Ratified the FCTC in December 2004. Particularly, in June 2012 the Viet Nam National Assembly approved of the country's first Tobacco Control Law, which has taken effect in May 2013. A number of important measures defined under the law aim at reducing both tobacco supply and consumption (National Assembly of Viet Nam, 2012).

Ample epidemiological studies have identified smoking as a learnt behavior and initiated during adolescence (American Cancer Society, 2015). Most smokers start smoking under the age of 18 (U.S. Department of Health and Human Services, 2012; Muzammil et al., 2015). Therefore, the simple fact is that the tobacco epidemic 
cannot be put to an end without efforts being focused on young people.

Previous studies on smoking adolescents in Asian countries identified that intrapersonal factors associated with adolescent smoking include lower levels of knowledge on the hazards of smoking among adolescents in China (Yan et al., 2014), positive attitudes towards smoking among Iranian adolescents (Nazarzdeh et al., 2013). In Malaysia, Lim et al. also found that adolescents with better knowledge on the hazards of smoking and negative attitudes towards smoking were less likely to smoke (Lim et al., 2015). A study in Teheran, Iran among 1,271 male students reported that the ratio of smoking in students was higher among those with inappropriate attitude towards it $(\mathrm{OR}=1.6)$. Those with poor knowledge had an inappropriate attitude and are predicted to have a higher chance of cigarette consumption in the next 5 years ( $\mathrm{p}<0.0001)$ (Heydari et al., 2013). The link among this body of evidence explains our interest in obtaining precise data on knowledge and attitude towards smoking among adolescents (Ramezankhani et al., 2010).

Exposure to anti-smoking intervention programs has been shown to improve adolescents' knowledge, attitudes towards smoking (Chen et al., 2014; Tahlil et al., 2015) and decrease smoking behaviors globally (Sun et al., 2007). Such programs aim at providing smoking-related health information through multiple channels such as mass media, schools and pursuing strategies based on social competence or social influence.

To help countries effectively monitor their youth smoking prevention and control efforts, the WHO's Tobacco Free Initiative and the Center for Disease Control and Prevention Office on Smoking and Health have developed the Global Youth Tobacco Survey (GYTS). Viet Nam conducted this survey three times in 2003, 2007 and 2014 among 13-15 aged students. The results showed that over more than ten years, overall cigarette smoking prevalence among students had decreased slightly from $4.09 \%$ in 2003 to $3.3 \%$ in 2007 but slightly increased from $3.3 \%$ to $3.5 \%$ between 2007 and 2014 (VINACOSH, 2003; VINACOSH, 2007; Ministry of Health et al., 2014).

Using data from GYTS Viet Nam 2014, the main objective of this paper is to describe tobacco-related knowledge, attitude and associations among school adolescents aged 13-15 with exposure to anti-smoking information. This evidence would contribute to the development of effective tobacco control programmes targeting this specific age group in Viet Nam and the region.

\section{Materials and Methods}

\section{Data source}

The paper used data from 2014 GYTS in Viet Nam. This is a school-based cross-sectional study involving children aged 13-15 years old. The study applied a standardized methodology for sampling, questionnaire development, data collection and data processing including weighting provided by the US Center for Disease Control (CDC). Among 3,553 students completed the survey, only 3,430 were in the age range of 13 to 15 . The overall response rate of the survey was $95.0 \%$. The final questionnaire in Viet Nam consisted of 76 questions. Core questions focused on seven topics including knowledge and attitudes towards tobacco smoking, information on tobacco control. Detailed information on this survey has been presented elsewhere (Giang et al., 2016).

\section{Measurements}

Dependent variables: The knowledge questionnaire contained 4 questions to test the students' general knowledge of common myths surrounding smoking, and the health consequences of smoking: 1) Do you think the smoke from other people's tobacco might be harmful to you? 2) Do you think smoking is harmful to health? 3) Do you think if you smoke for only 1 or 2 years, and then stop, it is not harmful to your health? 4) When someone started smoking, do you think it would be hard to quit?. Each question had 5 alternatives: a. Definitely not; b. Probably not; c. Probably yes; d. Definitely yes; e. Don't know. Scores were calculated as the sum of correct answers, with 4 being the highest possible score (giving correct answers to all four questions) and the lowest score was 0 (giving incorrect answers to all four questions).

The attitude questionnaire comprised of 3 questions to measure attitudes towards personal, social and environmental aspects of tobacco use: 1) Do you think young people who smoke have more or less friends than others? With the response of 3 alternatives: more friends, less friends, and not different from people who don't smoke. 2) In your opinion, does smoking make you more or less attractive? With the response of 3 alternatives: more attractive, less attractive, and not different from people who don't smoke. 3) Do you think smoking tobacco helps people feel more comfortable or less comfortable in ceremonies, parties or other social events? With the response of 3 alternatives: more comfortable, less comfortable, and no difference whether smoking or not smoking. The highest possible score was 3 (giving correct response to all 3 questions), representing a correct attitude of avoiding cigarette smoking and the lowest score was 0 (giving incorrect answers to all three questions).

Independent variables: Participants' gender and exposure to anti-smoking information were determined using the 2 following self-completed questions: 1) During the past 30 days, have you seen or heard any media messages on tobacco control on television, radio, Internet, panes, posters, newspapers, magazines or movies? 2) During the past 12 months, have you been taught about the dangers of tobacco use in school? We classified participants into three groups: exposure to 2 sources, 1 source of anti-smoking information and none at all.

\section{Data analysis}

Both descriptive and univariate analysis were conducted using statistical software SPSS 20. The analysis began with the calculation of percentages of the variables of interest. The figures were weighted to represent the total population of schools in Viet Nam. Univariate analysis was performed to identify the association between knowledge, attitude and levels of exposure to media anti-smoking 
messages and the dangers of tobacco use in school. In order to identify these associations, we classified participants into three levels of knowledge and attitude: having correct knowledge (giving correct answers to all four questions) and incorrect knowledge (giving correct answers from 3 to 0 ); having correct attitude (giving correct answers to all three questions) and incorrect attitude (giving correct answers from 2 to 0 ); and having both correct knowledge and attitude (correct answers to all knowledge and attitude questions); the rest having both incorrect knowledge and attitude. Significance was concluded at $\mathrm{p}<0.05$.

\section{Ethical considerations}

The study was presented and discussed among those who are in charge of health research at Ministry of Health and provincial authorities to get approval. Approval was also obtained from teachers, representatives of parents and students before carrying out the survey.

\section{Results}

Among 3,430 school children aged 13-15 years who participated in the survey, $49.1 \%$ were males and $50.9 \%$ were females. Current access to anti-smoking information among the studied adolescents by gender, including noticed anti-tobacco messages in the media in the past 30 days, and being taught about the dangers of tobacco use in the past 12 months in school were focuses of attention. The proportion of the study subjects having access to 0 , 1 , and 2 of the above-mentioned sources of anti-smoking information were $8.3 \%, 33.0 \%$, and $58.7 \%$, respectively. The percentages of female students who accessed both anti-tobacco information in the media and in school were statistically higher as compared to the corresponding figures of their male counterparts.

Table 1 summarizes data for the overall situation of knowledge and attitude of study participants towards cigarette smoking. A substantial percentage of students 13-15 years of age definitely thought that other people's tobacco smoking might be harmful to them and smoking is harmful to health ( $89.4 \%$ and $89.6 \%$ respectively). However, only $46.4 \%$ reported that it is definitely difficult to quit smoking once someone starts and $66.9 \%$ thought that smoking for only 1 or 2 years, once stopped, is harmful to health. Just more than half of the respondents reported that young smokers have fewer friends than others and smoking makes them less attractive as well as less comfortable in social events.

Figure 1 and Figure 2 present levels of correct responses to 4 questions measuring knowledge and 3 questions evaluating attitude toward tobacco smoking. Overall, there is little difference in the figures of correct knowledge and attitude towards tobacco smoking. The percentages of participants who gave correct answers to all 4 knowledge questions and 3 attitude questions are $32.8 \%$ and $30.6 \%$, respectively.

The proportion of studied adolescents having correct responses to all 4 questions on knowledge and 3 questions on attitude was only $11.8 \%$. The percentages having correct knowledge, attitude and both among school girls were significantly higher in comparison with the corresponding figures of boys (Table 1).

Table 2 shows the associations between levels of access to anti-smoking information and knowledge, attitude among school children. Clearly, school children who had access to anti-smoking information were likely to have

Table 1. Description of Knowledge and Attitude towards Tobacco Smoking among School Children aged 13-15 Vears by Gender in Viet Nam

\begin{tabular}{lccc}
\hline & Total & Male & Female \\
\cline { 2 - 4 } & \multicolumn{3}{c}{ Percentage (95\% CI) } \\
\hline Knowledge & & 91.3 \\
Definitely, the smoke from other people tobacco smoking & 89.4 & $(89.9-92.8)$ & 93.2 \\
might be harm to me & $(88.3-90.5)$ & $(85.5-89.1)$ & $(91.9-94.5)$ \\
Definitely, smoking is harmful to health & 89.6 & 85.7 & 69.0 \\
Definitely, smoke for only 1 or 2 years and after stopping, it & $(88.4-90.7)$ & $(83.8-87.6)$ & $(66.6-71.5)$ \\
is harmful to health & 66.9 & 64.7 & 46.6 \\
Definitely, when someone started smoking, it would be hard & $(65.2-65.7)$ & $(62.1-67.4)$ & $54.0-49.2)$ \\
to quit & $(44.4-48.4$ & 46.2 & $(55.9-61.1)$ \\
Attitude & & $(43.5-48.9)$ & 71.7 \\
Young people smoke that have fewer friends than others & 55.4 & 51.9 & $(69.3-74.0)$ \\
Smoking makes me less attractive & $(53.5-57.2)$ & $(49.2-54.6)$ & 55.8 \\
Smoking tobacco makes people feel less comfortable in the & 64.7 & 57.4 & $(53.3-58.5)$ \\
ceremonies, parties or other social events & $(62.9-66.5)$ & $(54.7-60.0)$ & 33.8 \\
Correct knowledge & 52.2 & 48.4 & $(31.2-36.2)$ \\
Correct attitude & $(50.4-54.1)$ & $(45.7-51.1)$ & 35.2 \\
Correct knowledge and attitude & $(31.0-34.5)$ & $(29.3-34.2)$ & $(32.9-37.8)$ \\
\hline
\end{tabular}




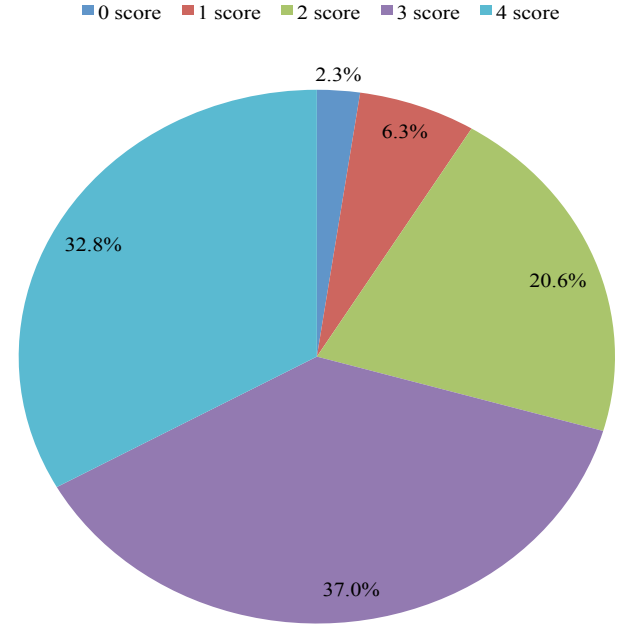

Figure 1. Levels of Knowledge on Tobacco Smoking among School Children aged 13-15 years in Vietnam

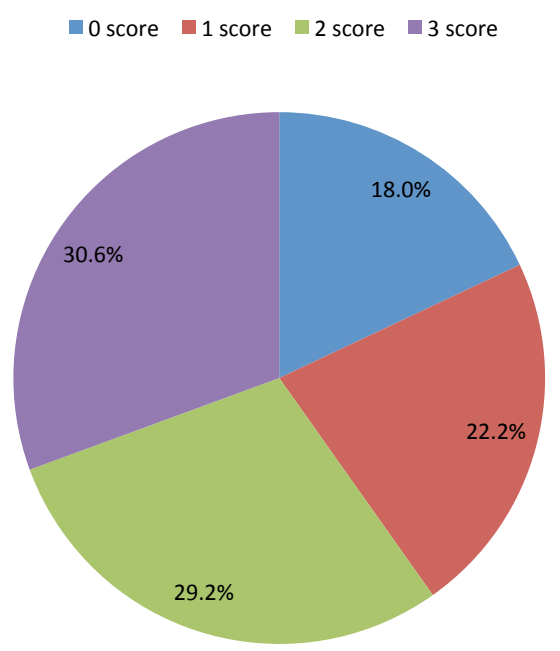

Figure 2. Levels of Attitude towards Tobacco Smoking among School Children aged 13-15 years in Vietnam

Table 2. Univariate Logistic Regression Analysis of Associations Between Levels of Access to Anti-smoking Information and Knowledge, Attitude among School Children aged 13-15 years in Viet Nam

\begin{tabular}{|c|c|c|c|}
\hline Level of access to anti-smoking information & Odds Ratio & \multicolumn{2}{|c|}{$95 \% \mathrm{CI}$} \\
\hline \multicolumn{4}{|c|}{ Dependent variable: Knowledge on tobacco smoking ( $1=$ correct, $0=$ incorrect $)$} \\
\hline None & 1 & & \\
\hline 1 source & 1.21 & 0.89 & 1.65 \\
\hline 2 sources & 1.63 & 1.21 & 2.20 \\
\hline \multicolumn{4}{|c|}{ Dependent variable: Attitude towards tobacco smoking ( $1=$ correct, $0=$ incorrect) } \\
\hline None & 1 & & \\
\hline 1 source & 1.43 & 1.03 & 1.99 \\
\hline 2 sources & 2.21 & 1.61 & 3.03 \\
\hline \multicolumn{4}{|c|}{ Dependent variable: Both Knowledge and Attitude towards tobacco smoking ( $1=$ correct, $0=$ incorrect $)$} \\
\hline None & 1 & & \\
\hline 1 source & 1.55 & 0.91 & 2.63 \\
\hline 2 sources & 2.30 & 1.38 & 3.82 \\
\hline
\end{tabular}

better knowledge, attitude towards tobacco smoking. Especially, noticing anti-smoking messages in the media within the past 30 days together with having lessons in school about the dangers of tobacco use in the past 12 months substantially increased the odds of having correct knowledge, appropriate attitudes and both $(\mathrm{OR}=1.63$, 95\%CI: 1.21-2.20; $\mathrm{OR}=2.21,95 \% \mathrm{CI}: 1.61-3.03 ; \mathrm{OR}=$ 2.30, 95\% CI: $1.38-3.82$, respectively).

\section{Discussion}

The rationale of this paper was to document the situation of knowledge and attitude towards tobacco use and their correlations with exposure to anti-smoking information among school children aged 13 to 15 in Viet Nam using data from GYTS, 2014. Results from the GYTS, 2014 confirm the findings from previous surveys in Viet Nam regarding good knowledge of tobacco's negative effects on health among school adolescents (Son et al., 2010). Among this study's respondents, $89.4 \%$ ( $87.3 \%$ boys and $91.3 \%$ girls) knew that other people's tobacco smoke is harmful to them. This result is substantially higher than that of Indonesian adolescents (72.5\%) indicated in GYTS report, 2014 (World Health
Organization, Regional Office for South-East Asia, 2014). When asked if smoking was harmful to health, about $89.6 \%$ of the students agreed that smoking caused health problems. There was gender difference regarding this opinion, wherein significantly more female students (93.2\% vs $85.7 \%$ ) agreed that smoking was harmful to health than male students. Similar findings $(88.0 \%$ in total; and $93.8 \%$ among females vs $81.6 \%$ among males) was also found from recent study among Malaysian school children (Caszo et al., 2015) and young adults in Mangalore, India where the majority of smokers in this study population (84\%) was conscious about the harmful effects of tobacco (Lalithambigai et al., 2016).

However, almost half of the school adolescents in Viet Nam (46.4\%) definitely thought that it was difficult to quit once someone started smoking tobacco. In addition, only about 1 in 2 school children believed that smoking tobacco made people feel less comfortable in ceremonies, parties or other social events and young people who smoked had fewer friends than others $(52.2 \%$ and $55.4 \%$ respectively). Thus, it is important to note that general knowledge on the danger of tobacco use might be good but more detailed understandings among children must be improved. The existence of common misconceptions 
among school students may also be a reason for them to start smoking. Our findings thus provide an updated insight into the problem of tobacco prevention and control among adolescents. More effective communication strategies for tobacco control with a focus on changing this attitude among students are urgently needed in Viet Nam. The inverse relationship between negative attitude towards smoking and the likelihood of becoming a weekly smoker that was consistently reported among Iranian and Malaysian adolescents (Nazarzdeh et al., 2013; Caszo et al., 2015) also supports this implication.

The government of Viet Nam has adopted a multipronged and multi-media strategy to raise awareness about the harmful effects of tobacco use, using a variety of educational products such as audiovisual spots, radio sports, advertisement in media, education and behavior change communication campaigns. This study indicated that communication coverage through media on tobacco control in Viet Nam has been effective as the anti-tobacco message reached $84.7 \%$ of children in a 30 -day period. However, this figure has slightly decreased in comparison with two previous surveys in 2003 and 2007 (about 90\%) (VINACOSH, 2003; VINACOSH, 2007). Currently, only nearly two third of the children $(64.7 \%)$ were taught about the danger of tobacco use in their school in a 12- month period. This is similar to the findings from the survey in 2003 with more than 6 in 10 students had been taught in school about the danger of smoking in five studied provinces (VINACOSH, 2003) but lower than that $(73.3 \%)$ of the study in 2007 (VINACOSH, 2007). The differences in proportions of school adolescents who noticed media messages on tobacco control and had been taught in class, during the past year, about the danger of smoking among the three surveys could be explained by the differences in characteristics of the study samples. However, the findings of current study are warranted to pay more attention to the coverage and effectiveness of tobacco control communication interventions targeted at adolescents in Viet Nam.

Furthermore, we also found the associations between exposure to tobacco control messages in media and being taught in school about the danger of tobacco smoking with knowledge and attitude of studied children. The students who received lessons on the dangers of smoking in class were less likely to report incorrect knowledge or inappropriate attitude or both. Similar correlations were also observed among those adolescents who noticed anti-tobacco messages in media in the past 30 days. Notably, according to the analysis, there were doseresponse associations that for children who accessed both sources of tobacco control information, the likelihood of having better knowledge and attitude towards tobacco smoking was substantially increased. These findings are in accordance with previous studies in both developed and developing countries. The anti-tobacco messages have been found to be effective in enhancing knowledge as well as in transforming attitudes and values of the self and community on tobacco use (Kaur, 2012) and the consequences of smoking among children and young people (Richardson et al., 2007). Extensive evidence found that greater exposure to tobacco control campaigns may reduce the likelihood of smoking initiation among the youth (Centers for Disease Control and Prevention, 2014). However, knowledge and perceptions of risks and harm are not enough. We must also have commitment to create a supporting environment that makes it harder for youth to smoke, to make cessation services accessible and affordable (Aryal, et al., 2014).

Data from GYTS provide a wealth of information on the knowledge, attitudes of Vietnamese adolescents with respect to smoking. However, as with other epidemiological research, the present study was subjected to limitations. Firstly, the sample surveyed was limited to youths attending school who may not be representative of all 13 to 15 year olds in Viet Nam. Secondly, data was selfreported by students, who may under or over-report their knowledge and attitude due to exchange of information while responding to the questionnaire. Thirdly, there is also a possibility of recall bias when GYTS's questions are asked about pro-tobacco advertisements and anti-smoking messages because both occurred simultaneously. Fourthly, the data collected from cross-sectional study did not allow for the establishment of a causal relationship between exposure to tobacco control information and knowledge as well as attitude of school adolescents. Fifthly, applying univariate analysis in this paper results in a limitation that it does not account for the interdependence of the independent variables.

In conclusion, despite these limitations, our results provide important information about the knowledge of and attitude toward tobacco smoking among Vietnamese adolescents. Despite the relatively high awareness of the harmful effects of smoking, there is still room for improvement regarding the level of comprehensive knowledge and attitude. Knowledge and attitude related to tobacco use in the present study are better among school girls than boys. Greater exposure to tobacco control information may increase the likelihood of having better knowledge and more appropriate attitude. Considering our study findings, the planning and implementation of effective educational tobacco control programs are urgently needed as preventing the initiation of a habit is far easier than stopping it.

\section{Acknowledgements}

We thank the VINACOSH (Vietnam Steering Committee on Smoking and Health) and the GYTS team of Vietnam for making these data available. We also thank WHO's Tobacco Free Initiative (TFI) and CDC's Office on Smoking and Health for providing technical assistances. We acknowledge the financial support and coordination of the Hanoi School of Public Health, World Health Organization and the Tobacco Control Research group of Vietnam Tobacco Control Fund. We also would like to express our sincere appreciation for Dr. Malcolm Moore, the Editor in Chief of the Asian Pacific Journal of Cancer prevention, for his great inputs to this paper).

\section{References}


Nguyen Thanh Huong et al

American Cancer Society. The Tobacco Atlas (Fifth Edition) (2015). CH11_smoking-Among-Youth.

Aryal UR, Petzold M, Bondjers G, Krettek A (2014). Correlates of smoking susceptibility among adolescents in a peri-urban area of Nepal: a population-based cross-sectional study in the jhaukhel-duwakot health demographic surveillance site. Glob Health Action, 7, 24488.

Caszo B, Khair M, Mustafa MH, et al (2015). Common misconceptions and future intention to smoke among secondary school students in Malaysia. Asian Pac J Cancer Prev, 16, 1159-64.

Centers for Disease Control and Prevention (CDC) (2014). Best Practices for Comprehensive Tobacco Control Programs - 2014. Atlanta: U.S. Department of Health and Human Services, Centers for Disease Control and Prevention, National Center for Chronic Disease Prevention and Health Promotion, Office on Smoking and Health.

CDC, WHO (2010). Global Adult Tobacco Survey (GATS) Viet Nam 2010. Ha Noi.

Chen L, Chen Y, Hao Y, Gu J, Guo Y, Ling W (2014). Effectiveness of school-based smoking intervention in middle school students of Linzhi Tibetan and Guangzhou Han ethnicity in China. Addictive Behaviors, 39, 189-95.

Giang KB, Minh HV, Hai PT and et al (2016). Methodology of global youth tobacco use survey (GYTS) in Viet Nam, 2014. Asian Pac J Cancer Prev, 17 Tobacco Prevention and Control in Viet Nam Suppl, 11-15.

Heydari G, Yousefifard M, Hosseini M, Ramezankhani A, Masjedi MR (2013). Cigarette smoking, knowledge, attitude and prediction of smoking between male students, teachers and clergymen in Tehran, Iran, 2009. Int J Prev Med, 4, 557-64.

Kaur J, Kishore J, Kumar M (2012). Effect of Anti-Tobacco Audiovisual Messages on Knowledge and Attitude towards Tobacco Use in North India. Indian J Community Med, $\mathbf{3 7}$, 227-31.

Lalithambigai G, Rao A, Rajesh G, Ramya S, Pai BHM (2016). Predictors of cigarette smoking among young adults in Mangalore, India. Asian Pac J Cancer Prev, 17, 45-50.

Lim HK, The HC, Lim LH, et al (2015). Smoking among secondary school students in Kota Tinggi, Johor, Malaysia - findings from a cross-sectional study. Asian Pac J Cancer Prev, 16, 4563-70.

Ministry of Health of Viet Nam, VINACOSH, Hanoi Medical University, et al (2014). Report of Global Youth Tobacco Use Survey (GYTS 2014) in Viet Nam.

Muzammil K, Singh S, Singh VJ, et al (2015). A cross-sectional study of tobacco addiction among college students of Muzaffarnagar City. Indian J Comm Health, 27, 125-29.

National Assembly of Vietnam (2012). The Law on Prevention and Control of Tobacco harms.

Nazarzdeh M, Bidel Z, Ayuni E, et al (2013). Smoking staus in Iranian male adolescents: a cross sectional study and a meta-analysis. Addict Behav, 38, 2214-18.

Ramezankhani A, Zaboli FS, Zarghi A, Masjedi MR, Heydari GR (2010). Smoking habits of adolescent students in Tehran. Tanaffos, 9, 33-42.

Richardson L1, Hemsing N, Greaves L, et al (2009). Preventing smoking in young people: a systematic review of the impact of access interventions. Int J Environ Res Public Health, $\mathbf{6}$, 1485-514.

Son DM, Anh TQ, Bich NN, Thuan TV, Dieu B, Nga NHT (2010). Knowledge, attitude and practice on tobacco smoking at hung dao high school in hai duong province. Ho Chi Minh City Medical J, 14, 83-91.

Sun P, Miyano J, Rohrbach LA, Dent CW, Sussman S (2007). Short-term effects of Project EX-4: a classroom-based smoking prevention and cessation intervention pro-gram. Addictive Behaviors, 32, 342-50.

Tahlil T, Woodman RJ, Coveney J, and Ward PR (2015). Sixmonths follow-up of a cluster randomized trial of schoolbased smoking prevention education programs in Aceh, Indonesia. BMC Public Health, 15, 1088.

U.S. Department of Health and Human Services (2012). Preventing tobacco use among youth and young adults: a report of the surgeon general. atlanta, ga: u.s. department of health and human services, centers for disease control and prevention, national center for chronic disease prevention and health promotion, office on smoking and health.

VINACOSH (2003). The 2003 GYTS in Viet Nam: A preliminary report on youth tobacco use.

VINACOSH (2007). Viet Nam National (aged 13-15)-GYTS. Factsheet.

Vietnam Steering Committee on Smoking and Health (VINACOSH) and Southeast Asia tobacco control alliance (SEATCA) (2014). The ASEAN Tobacco Control Report.

World Health Organization, Regional Office for South-East Asia. Global Youth Tobacco Survey (GYTS) (2015). Indonesia report, 2014. New Delhi: WHO-SEARO.

World Health Organization (2011). WHO report on the global tobacco epidemic, 2011: warning about the dangers of tobacco.

World Health Organization (2014). World health statistics 2014.

Yan Y, Jacques-Tiura AJ, Chen XG (2014). Application of the Protection Motivation Theory in predicting cigarette smoking among adolescents in China. Addic Behav, 39, 181-8. 